\title{
Causes of Variation Orders in Road Construction Projects in Sri Lanka
}

\author{
R. U. Halwatura and N. P. N. P. Ranasinghe \\ Department of Civil Engineering, University of Moratuwa, 10400 Moratuwa, Sri Lanka \\ Correspondence should be addressed to R. U. Halwatura; rangikauh@gmail.com
}

Received 30 September 2013; Accepted 27 October 2013

Academic Editors: J. de Brito and S. P. Low

Copyright (C) 2013 R. U. Halwatura and N. P. N. P. Ranasinghe. This is an open access article distributed under the Creative Commons Attribution License, which permits unrestricted use, distribution, and reproduction in any medium, provided the original work is properly cited.

\begin{abstract}
One of the most important problems in the construction industry is variations. They occur in every construction project and the magnitude of these variations varies considerably from project to project. Hence, the variations orders bear great importance right from the inception to completion in the construction industry. Most of the road construction projects in Sri Lanka have experienced a large number of variation orders. The client had to spend more than what was initially estimated in most cases. Sometimes, disputes and unnecessary delays occur due to variations. This study attempted to reveal the possible causes of variation orders in the road construction projects in Sri Lanka. The data were collected through a literature review, a case study analysis focused on 11 road construction projects, and a questionnaire administered to professionals in the road construction industry in Sri Lanka. The study found out that the causes in the local context differ from those in the international context. According to the questionnaire survey, poor estimation was the most significant cause of variation orders. Unforeseen site conditions, political pressure during construction stage, poor investigation, and client-initiated variations occupy the 2 nd to 5 th places, respectively, in the ranking. This ranking was further proven through the case study analysis.
\end{abstract}

\section{Introduction}

The cost of a construction project is one of the most important factors in the construction industry. Due to many reasons, the total cost of a project can significantly vary from the initial estimated cost. The reasons could be changes in scope of work, specifications, or any other contract documents. In the construction industry, variation orders are created when changes occur. It is an official document that states the changes made into the original agreement between the client and the contractor. When a variation order is created, it brings several negative effects to both the client and the contractor.

The study discussed in this paper was aimed at investigating possible causes of variation orders in the road construction projects in Sri Lanka. The data for the analysis were collected using three methods. The causes of variation orders in general in the road construction industry and their ranking were identified based on a literature review. Then the findings were surveyed based on a questionnaire administered to the professionals in the industry in Sri Lanka and selective case studies were analyzed to understand the degree of occurrence and their impact.

This paper first provides a brief literature review to discuss the theoretical background to the study and then it discusses the methodology used in the study, results with discussion, and finally the main conclusions with some recommendations.

\section{The Literature Review}

The cost of a construction project right from inception to completion bears great importance in the construction industry. However, due to many reasons, the total cost of a project can significantly vary from the initial estimated cost. These variations are inevitable in any construction project [1]. Fisk [2] defines the following: "a variation is any deviation from an agreed well-defined scope and schedule. Stated differently, this is a change in any modification to the 


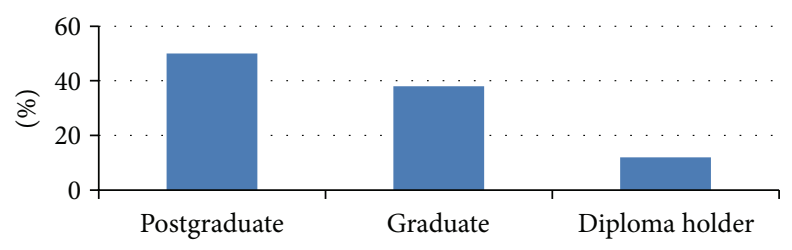

FIGURE 1: Educational background of the respondents.

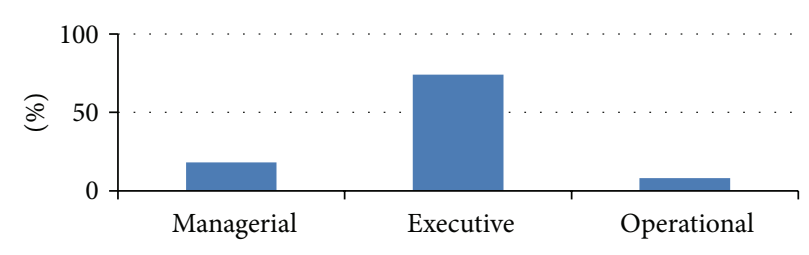

FIGURE 2: Occupation level of the respondents.

contractual guidance provided to the contractor by the owner or owner's representative." This includes changes to plans, specifications, or any other contract documents.

Clearly, in construction terms, variability is referred to as variation orders. A variation order is the formal document that is used to modify the original contractual agreement provided to the contractor by the client or the client's representative and becomes part of the project's documents [35]. Arguably, variation orders may be seen as counter to the principle of waste reduction. The more the variation orders are on a project, the greater the likelihood that they become time consuming and costly elements in construction projects is [6]. When a variation order occurred, the contractor tends to charge higher rates for variation items. Then the client is affected in terms of cost.

Success in managing variation orders results in uninterrupted construction operations and agreed project costs as well as duration [7]. However, this is not always practically achievable. A variation order has to be managed carefully. Otherwise, disputes between a client and a contractor related to cost and time of work might occur [7]. Variation orders often involve additional cost and disruption to work already underway, leading to cost and time overruns, quality degradation, and loss in productivity on construction projects [8].

Previous studies related to variation orders have mainly focused on management aspects and their overall costs $[6,7$, 9]. A study of delays and cost increases in the construction of private residential projects in Kuwait revealed that a number of variation orders issued during the construction phase led to both delays and cost increases [10]. The projects that experienced variation orders incurred more than 58\% time delay and cost increases when compared to those with no variation orders [10]. The magnitude of variation orders varies from one project to another. Though there have been cases where variation costs accounted for as much as $100 \%$ of the budgeted funds, the industry norm has been determined to be about $10 \%$ [5]. A study by Charoenngam et al. [7] of variation orders on construction projects found that the average cost escalation was $7 \%$ of the original project cost with an average time extension of $30 \%$ than the originally stipulated project duration. Studies have also revealed that the significant reduction in both cost increase and time delay can be achieved through a complete design before commencement of work on site resulting in the prevention of variation orders [10].

Variation orders not only affect project performance in terms of time and cost but also adversely affect the quality, health, safety, and professional relations [5]. However, factors influencing the occurrence of variation orders and their adverse impact on project performance vary from one project to another. Factors include the nature of work, the complexity of the project, and the procurement method. Though it is likely that variation orders cannot be avoided completely, they can be minimized or prevented if their origin and causes were clearly known [6]. The successful execution of construction projects and keeping them within the estimated cost and prescribed schedules depend on methodology that requires sound engineering judgment [11].

One of the most important problems in the road construction industry in Sri Lanka seems to be managing variation orders. There is less literature available on this area; however, Pathiranage and Halwatura [12] have found in their study that one of the main causes of project delay is variation orders. Moreover, Nowfal and Gunawardana [13] stated that the variation order is a key factor which is contributing to price overrun in this industry.

This present study attempted to reveal the possible causes of variation orders in road construction projects in Sri Lanka. As the data collection was done through case study analysis and questionnaire survey, the accuracy of the data in the Sri Lankan context depends on the quality of the responses/respondents.

The main objectives of the study were as follows:

(1) to find the causes of variation orders in the road construction industry in the international context through a literature review,

(2) to find the causes of variation orders in road projects in Sri Lanka using a case study analysis and rank them based on the number of occurrences and percentage 


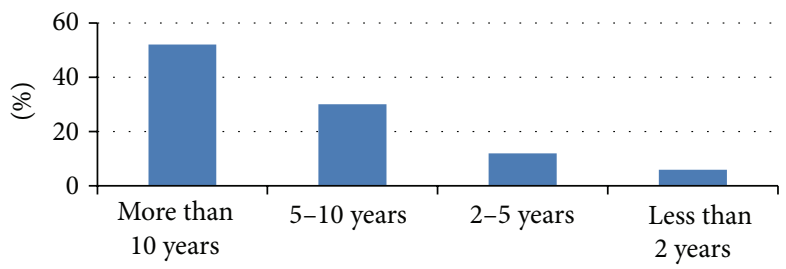

FIGURE 3: Number of years of working experience.
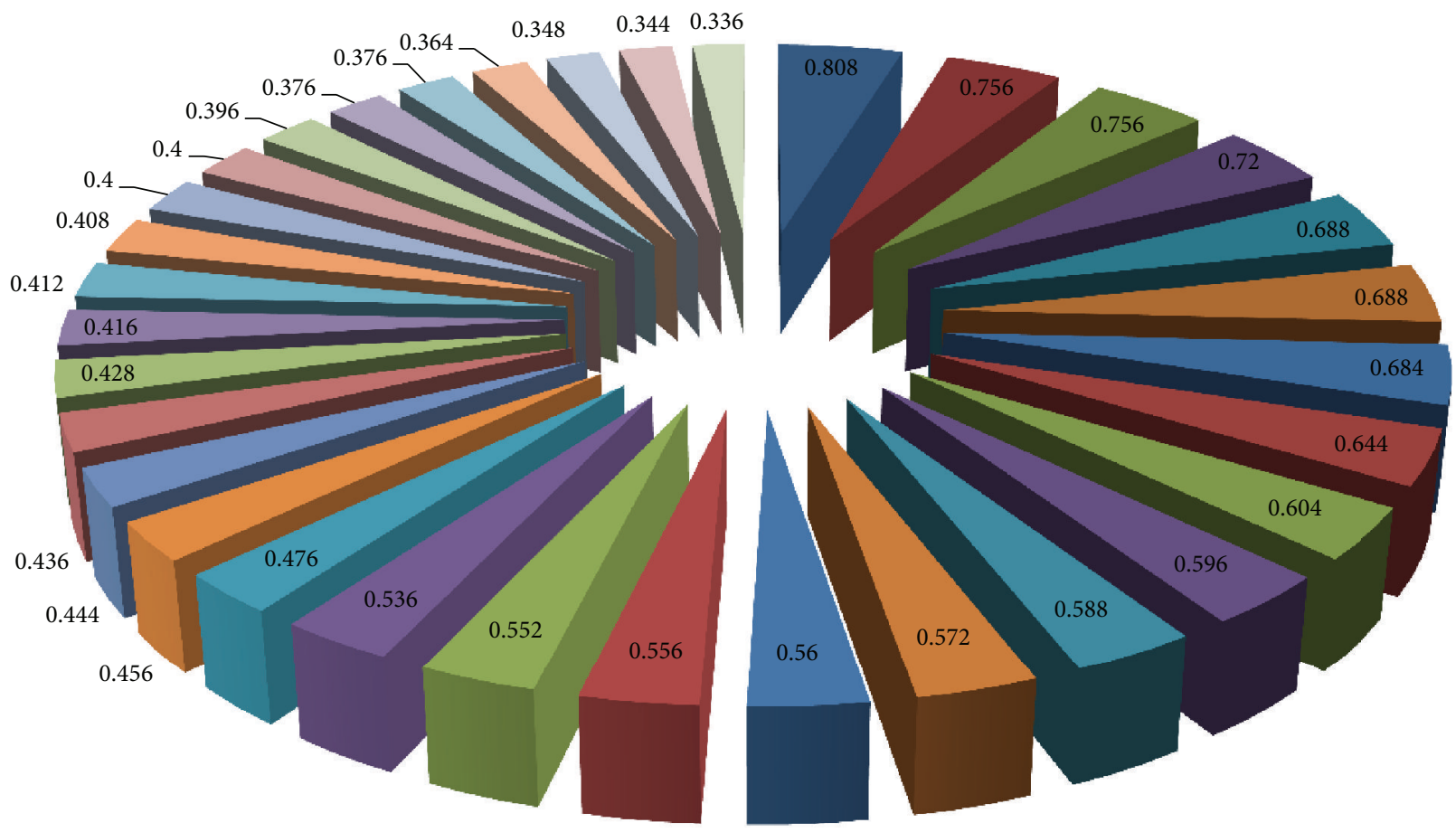

- Poor estimation

- Political pressure

- Unforeseen site conditions

- Client-initiated variations

- The scope of work for the contractor is not well defined

- Poor investigation

- Natural disasters

- Unrealistic contract durations imposed by client

- The objective of the project is not well defined

- Change in design by consultant/design changes

- Errors and omissions in design

- Poor performance of subcontractors

- Delay in approval

- Contractor's desire to improve his financial situation

- Other organizations

- Workmanship or material not meeting requirement of specifications

- Additional preliminaries due to time extension

- Defective workmanship

- Substitution of material and procedure

- Conflict between project documents

- Safety considerations

- Value engineering

Technology change

FIGURE 4: Ranking of variation causes based on relative importance index (RII).

variation for each cause with respect to the initial value without contingencies,

(3) to validate the findings using a questionnaire survey administered to industry experts and then rank them using the relative importance index (RII).

\section{Conceptual Framework and Methodology}

The preliminary data for this research was collected through a literature review and a case study analysis. Further, a questionnaire was administered to professionals in the road construction industry in Sri Lanka. The literature review was 


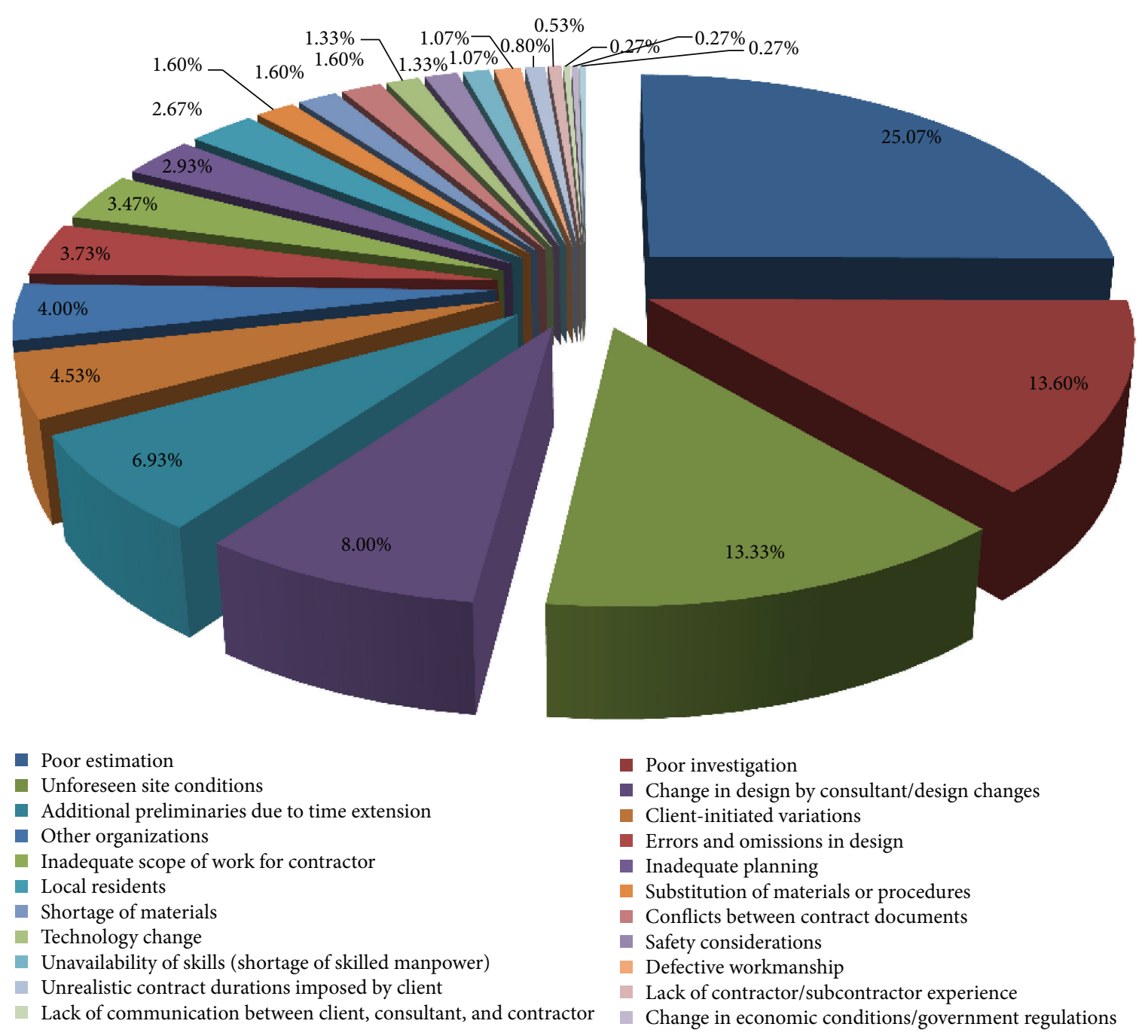

FIGURE 5: Ranking of causes based on number of occurrence in case studies.

done through books, conference proceedings, the Internet, and construction management and engineering journals.

The case study analysis was carried out for eleven project documents from recently completed road projects in Sri Lanka. An unbiased random sample of causes for variation orders was studied in order to predict the nature of the population (general circumstances) using statistical inference. RII was compiled based on the results of the questionnaire survey.

\section{Results and Discussion}

An effective analysis of variations and variation orders requires a comprehensive understanding of the root causes of variations [14]. Causes of variation orders were identified by many researchers $[2,15-20]$. Based on their findings, 55 causes of variation orders were identified. Then they were grouped under four categories: owner related variations, consultant related variations, contractor related variations, and other variations. These findings were used to develop the questionnaire.

In this study, 50 respondents participated representing distinct road construction projects. Their background was analyzed with respect to their education, the level of occupation, and the number of years of working experience. While Figure 1 shows the respondents' educational background, Figures 2 and 3 highlight the occupation level and the experience, respectively.

Out of 55 causes identified through the initial literature review, 33 were shortlisted based on the pilot surveys conducted on the selected case studies. Based on the successful respondents, RII was calculated to rank the causes. Figure 4 highlights the RII values for 33 causes, which were checked at the questionnaire survey.

375 variation orders were found in 11 selected projects and they were analyzed based on occurrence as well as significance. Figure 5 highlights the ranking based on the number of occurrences and Figure 6 shows their total percentage 


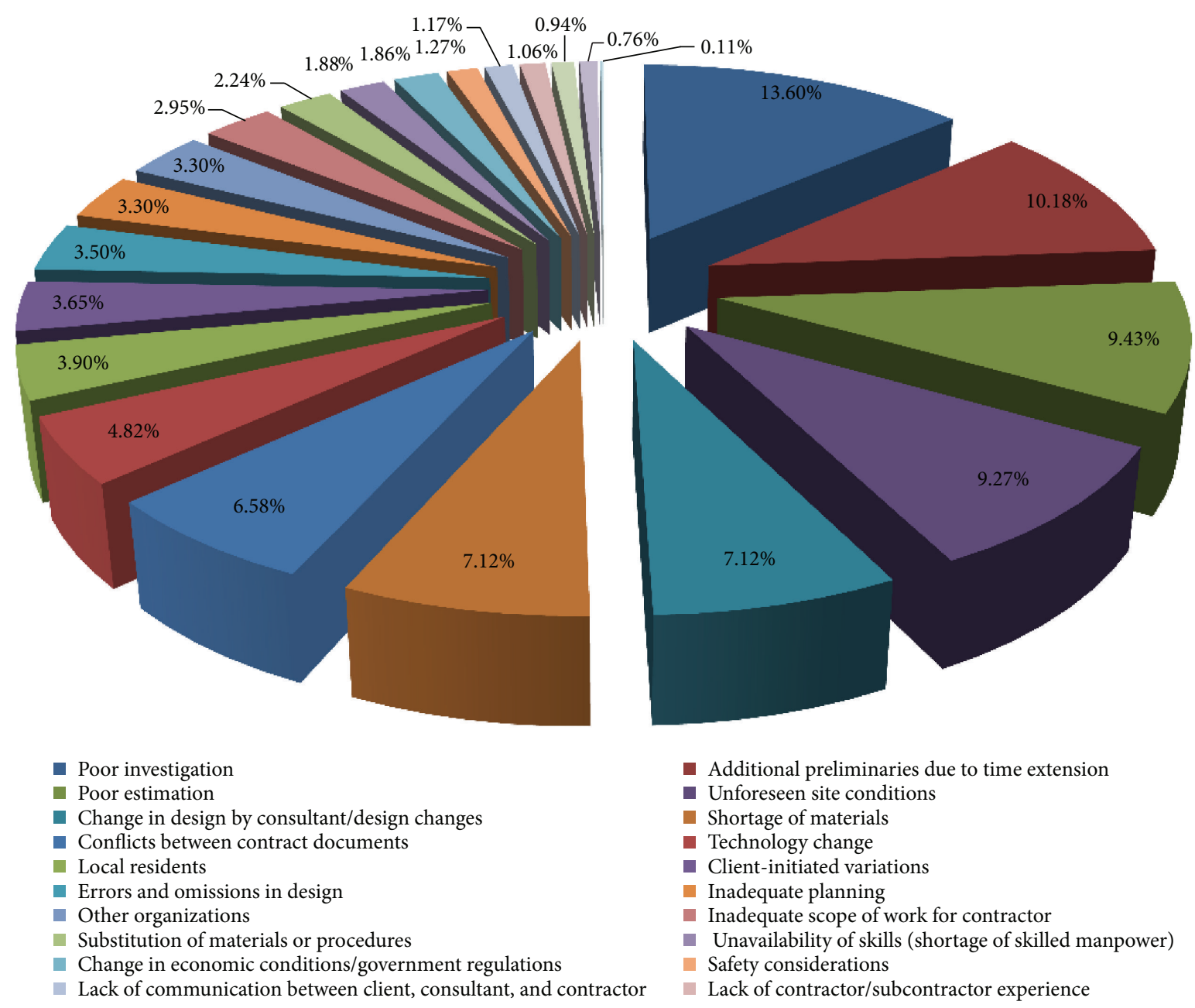

FIgURE 6: Contribution of each factor to variation.

contribution towards the finial variation of the project in terms of cost.

These three separate findings are compiled into Table 1 together with the ranking found in the literature review.

According to the questionnaire survey, poor estimation was the most significant cause of variation orders. Unforeseen site condition was the second cause. Further, political pressure during construction stage, poor investigation, and client-initiated variations are at the $3 \mathrm{rd}$, 4th, and 5 th places in the ranking, respectively. According to the number of occurrence of the case study survey, poor estimation is the most significant factor. Poor investigation follows it. The rank of unforeseen site conditions is at the third place. Further, change in design by consultant/design changes and additional preliminaries due to time extension are at the 4 th and 5 th places in the ranking.

Based on the monitory value of the claims, poor investigation, additional preliminaries due to extension of time, poor estimation, unforeseen site conditions, and change in design by consultant/design changes are the first 5 causes, respectively.
The literature review suggests a slightly different scenario. According to that, client-initiated variations are the most significant factor. Further, change of plans by owner, substitution of material and procedure, errors and omission of design, owner's financial problems, and change in design by consultant are at 2-6, respectively, in the ranking.

It is apparent that the most significant factors that cause variation orders in the international context are not significant in the Sri Lankan context. Moreover, some causes which are not within the first twenty factors in the international context are more significant in the Sri Lankan context. For example, poor investigation and poor estimation are within the first four factors in the Sri Lankan context; however, internationally, they are not within the top 20 factors. According to the questionnaire survey results, political pressure experienced by professionals during the construction stage and owner financial problems are key factors for variation orders but they have not been documented.

Extension of time is considered a dominant factor for variation orders; however, professionals have not indicated it. Client seems to be a dominant factor for variation orders in both international and local contexts. 
TABLE 1: Comparison of ranks of each analysis.

\begin{tabular}{|c|c|c|c|c|}
\hline Variation order cause & $\begin{array}{l}\text { Number of } \\
\text { occurrence }\end{array}$ & $\begin{array}{c}\text { Percentage } \\
\text { variation }\end{array}$ & Questionnaire & $\begin{array}{c}\text { Literature } \\
\text { review }\end{array}$ \\
\hline Poor estimation & 1 & 3 & 1 & - \\
\hline Poor investigation & 2 & 1 & 4 & - \\
\hline Unforeseen site conditions & 3 & 4 & 2 & 8 \\
\hline Change in design by consultant/design changes & 4 & 5 & 11 & 5 \\
\hline Additional preliminaries due to time extension & 5 & 2 & 24 & - \\
\hline Client-initiated variations & 6 & 10 & 5 & 1 \\
\hline Other organizations & 7 & 13 & 20 & - \\
\hline Errors and omissions in design & 8 & 11 & 12 & 3 \\
\hline Inadequate scope of work for contractor & 9 & 14 & 10 & - \\
\hline Inadequate planning & 10 & 12 & 15 & 7 \\
\hline Local residents & 11 & 9 & 17 & - \\
\hline Substitution of materials or procedures & 12 & 15 & 28 & 2 \\
\hline Shortage of materials & 13 & 6 & 19 & - \\
\hline Conflicts between contract documents & 14 & 7 & 30 & 6 \\
\hline Technology change & 15 & 8 & 33 & 13 \\
\hline Safety considerations & 16 & 18 & 32 & 12 \\
\hline Unavailability of skills (shortage of skilled manpower) & 17 & 16 & 29 & 16 \\
\hline Defective workmanship & 18 & 21 & 26 & 18 \\
\hline Unrealistic contract durations imposed by client & 19 & 22 & 8 & - \\
\hline Lack of contractor/subcontractor experience & 20 & 20 & 14 & - \\
\hline Lack of communication between client, consultant, and contractor & 21 & 19 & 25 & 7 \\
\hline Change in economic conditions/government regulations & 22 & 17 & 9 & 19 \\
\hline Political pressure & 23 & 23 & 3 & - \\
\hline Owner's financial problems & - & - & 5 & 4 \\
\hline The objective of the project is not well defined & - & - & 10 & 14 \\
\hline The scope of work for the contractor is not well defined & - & - & 7 & 9 \\
\hline Value engineering & - & - & 31 & 12 \\
\hline Contractor's desire to improve his financial situation & - & - & 18 & 10 \\
\hline The contractor's financial difficulties & - & - & 23 & 11 \\
\hline Weather conditions & - & - & 13 & 17 \\
\hline Natural disasters & - & - & 6 & - \\
\hline Delay in approval & - & - & 16 & - \\
\hline Consultant's lack of judgment and experience & - & - & 21 & - \\
\hline Workmanship or material not meeting requirement of specifications & - & - & 22 & 15 \\
\hline The required tools and equipment are not available & - & - & 27 & 18 \\
\hline
\end{tabular}

\section{Conclusions and Recommendations}

This study was focused on possible causes of variation orders in road construction projects in Sri Lanka. The data for the analysis were collected using three methods. The data related to causes of variation orders and their rankings were gathered based on a literature review. Then the findings were surveyed based on a questionnaire administered to the professionals in the road construction industry in Sri Lanka and several selected case studies were analyzed to understand the degree of occurrence and their impact.
This study identified that poor estimation is the main cause of variation orders in the road construction industry in Sri Lanka. For example, the consultants do not carry out adequate investigations at the initial investigation and design stage. Therefore, several site conditions rise in the construction stage. Further, clients do not have capable professional staff to carry out investigations and estimates, which are prepared by consultants and are not accurate in most cases. Therefore, several unnecessary variations occur during the construction stage. Apart from this main cause, most of the time, the fault of the client is not pointed out and 
not documented. Contractors and consultants are reluctant to point out client's faults, considering their survival in the construction industry. According to the questionnaire results, political pressure during construction stage is identified as a dominant factor. However, in case studies, they are not documented. Professionals do not seem to consider that the extension of allocated time is a critical factor for variations. However, according to the case studies, it is a critical factor.

Based on these findings it is possible to conclude that the Sri Lankan context should pay attention to several factors to minimize the occurrence of variation orders. The investigation must be carried out properly by qualified professional staff at the initial stage (in the pretender period) and adequate planning in advance is required by all involved parties before work starts at the site. The estimates have to be prepared properly by experienced professionals and clients should provide a clear brief of the scope of work. Further, consultants should ensure that the design/specifications fall within the approved budget and the budget team should be appointed early and they should participate in the designing process. Further, all parties should forecast unforeseen situations. Closer consultant coordination is required at the design stage, and utilization of an experienced consultant to produce a concluding design, working drawings, and contract drawings should be done at the tender stage. Further, maintaining proper communication channels and documentation is very important in terms of variation order management.

\section{References}

[1] C. W. Ibbs, C. K. Wong, and Y. H. Kwak, "Project change management system," Journal of Management in Engineering, vol. 17, no. 3, pp. 159-165, 2001.

[2] E. R. Fisk, Construction Project Administration, Prentice Hall, Upper Saddle River, NJ, USA, 5th edition, 1997.

[3] J. J. O’Brien, Construction Change Orders, McGraw-Hill, New York, NY, USA, 1998.

[4] FIDIC, "MDB Hardmonised Conditions of Contract for Construction-General Conditions," 2005.

[5] F. M. Arain and L. S. Pheng, "How design consultants perceive causes of variation orders for institutional buildings in Singapore," Architectural Engineering and Design Management, vol. 1, no. 3, pp. 181-196, 2005.

[6] A. A. Mohamed, Analysis and management of change orders for combined sewer over flow construction projects [Ph.D. Dissertation], Wayne State University, 2001.

[7] C. Charoenngam, S. T. Coquinco, and B. H. W. Hadikusumo, "Web-based application for managing change orders in construction projects," Construction Innovation, vol. 3, pp. 197-215, 2003.

[8] A. P. C. Chan and C. M. Yeong, "A comparison of strategies for reducing variations," Construction Management and Economics, vol. 13, no. 6, pp. 467-473, 1995.

[9] F. M. Arain, "Strategic management of variation orders for institutional building: leveraging on information technology," in Proceedings of the PMI Global Congress Proceedings, pp. 1-17, Toronto, Canada, 2005.

[10] P. A. Koushki, K. Al-Rashid, and N. Kartam, "Delays and cost increases in the construction of private residential projects in
Kuwait," Construction Management and Economics, vol. 23, no. 3, pp. 285-294, 2005.

[11] A. H. Al-Momani, "Construction delay: a quantitative analysis," International Journal of Project Management, vol. 18, no. 1, pp. 51-59, 2000.

[12] Y. L. Pathiranage and R. U. Halwatura, "Factors influencing the duration of road construction projects in Sri Lanka," ENGINEER Journal, vol. 43, no. 4, pp. 17-30, 2010.

[13] M. A. M. Nowfal and N. D. Gunawardana, Study of contract Price Overunn with particular emphasis on claim situations in road and bridge contracts in the road development authority [M.S. thesis], University of Moratuwa, Katubedda, Sri Lanka, 1997.

[14] W. Hester, J. A. Kuprenas, and T. C. Chang, "Construction changes and change orders: their magnitude and impact," $\mathrm{CII}$ Source Document 66, University of California-Berkeley, 1991.

[15] CII, The Impact of Changes on Construction Cost and Schedule, Construction Industry Institute, University of Texas at Austin, Austin, Tex, USA, 1990.

[16] H. R. Thomas and C. L. Napolitan, "Quantitative effects of construction changes on labor productivity," Journal of Construction Engineering and Management, vol. 121, no. 3, pp. 290-296, 1995.

[17] R. H. Clough and G. A. Sears, Construction Contracting, John Wiley \& Sons, New York, NY, USA, 6th edition, 1994.

[18] J. Wang, N. Fisher, C. Sun, and D. Wu, "An analysis of the distribution of time variance for building projects," The International Journal of Construction Management, vol. 3, no. 1, pp. 73-82, 2003.

[19] Y. Wang, "Coordination issues in Chinese large building projects," Journal of Management in Engineering, vol. 16, no. 6, pp. 54-61, 2000.

[20] F. M. Arain and L. S. Pheng, "The potential effects of variation orders on institutional building projects," Facilities, vol. 23, no. 11-12, pp. 496-510, 2005. 

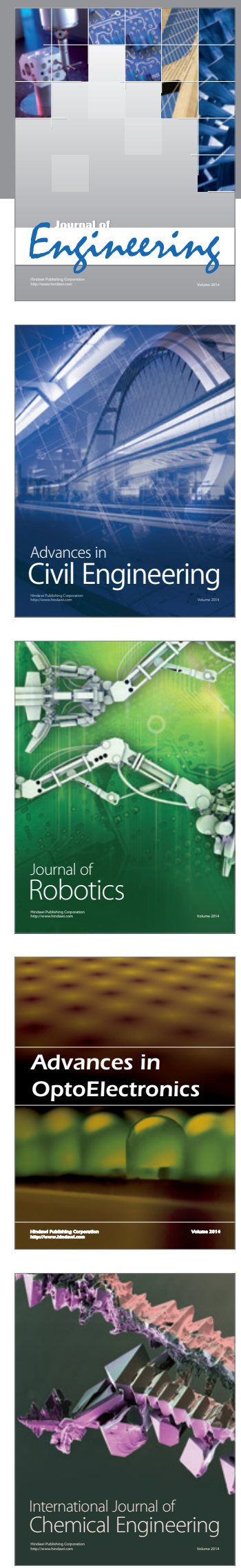

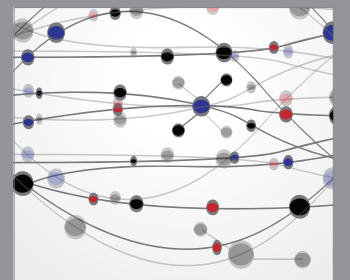

The Scientific World Journal
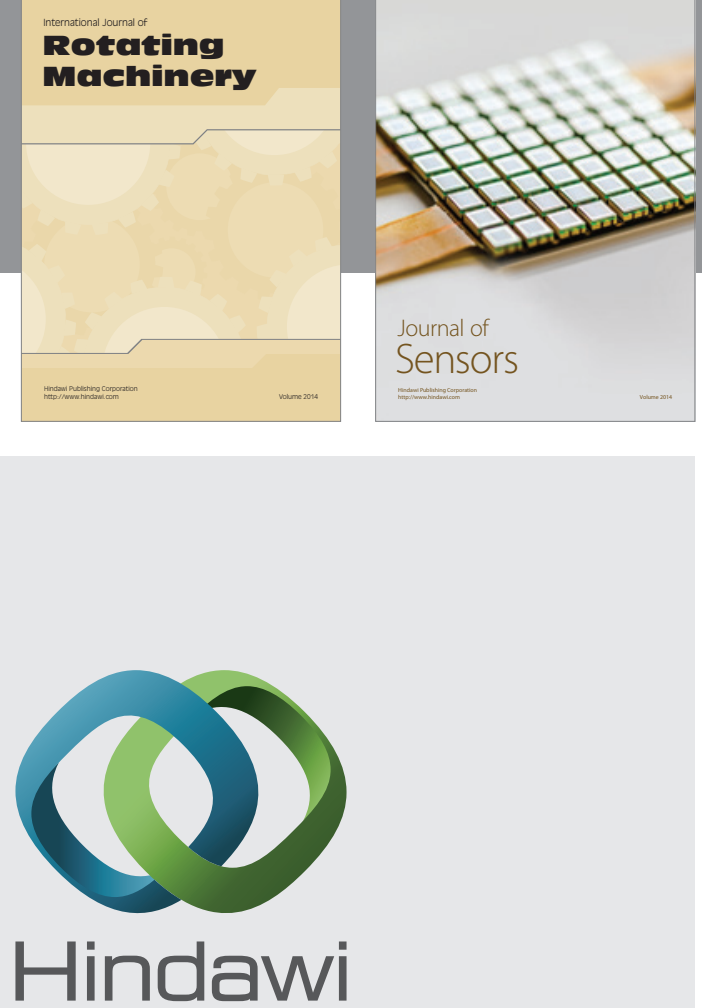

Submit your manuscripts at http://www.hindawi.com
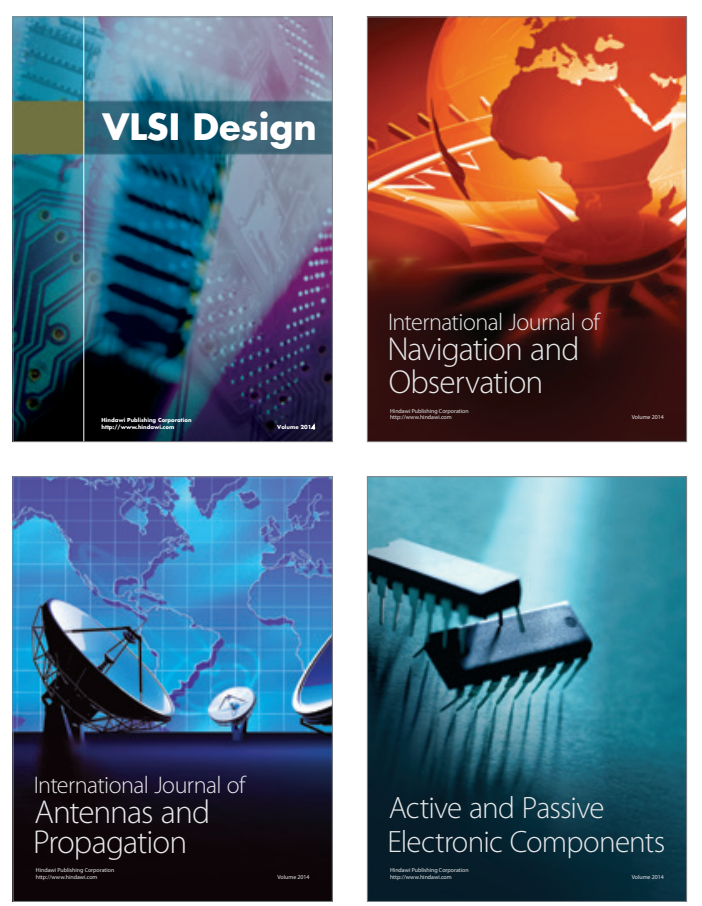
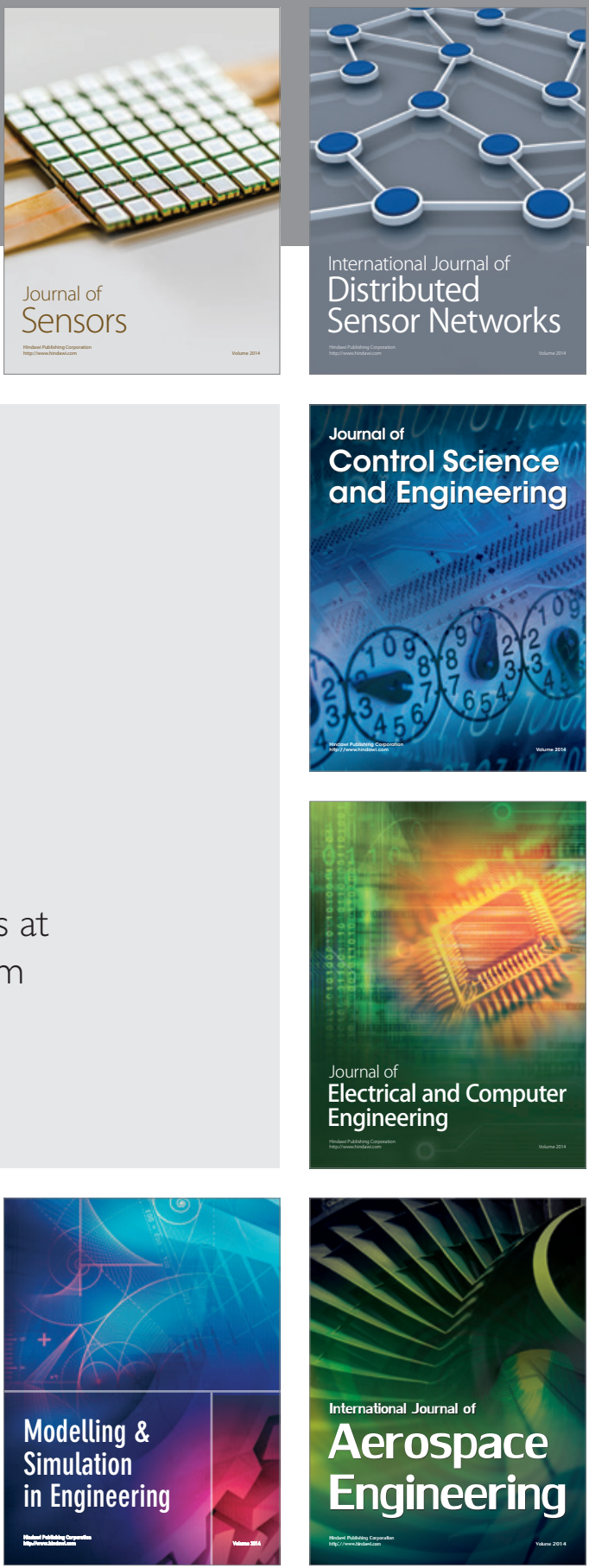

Journal of

Control Science

and Engineering
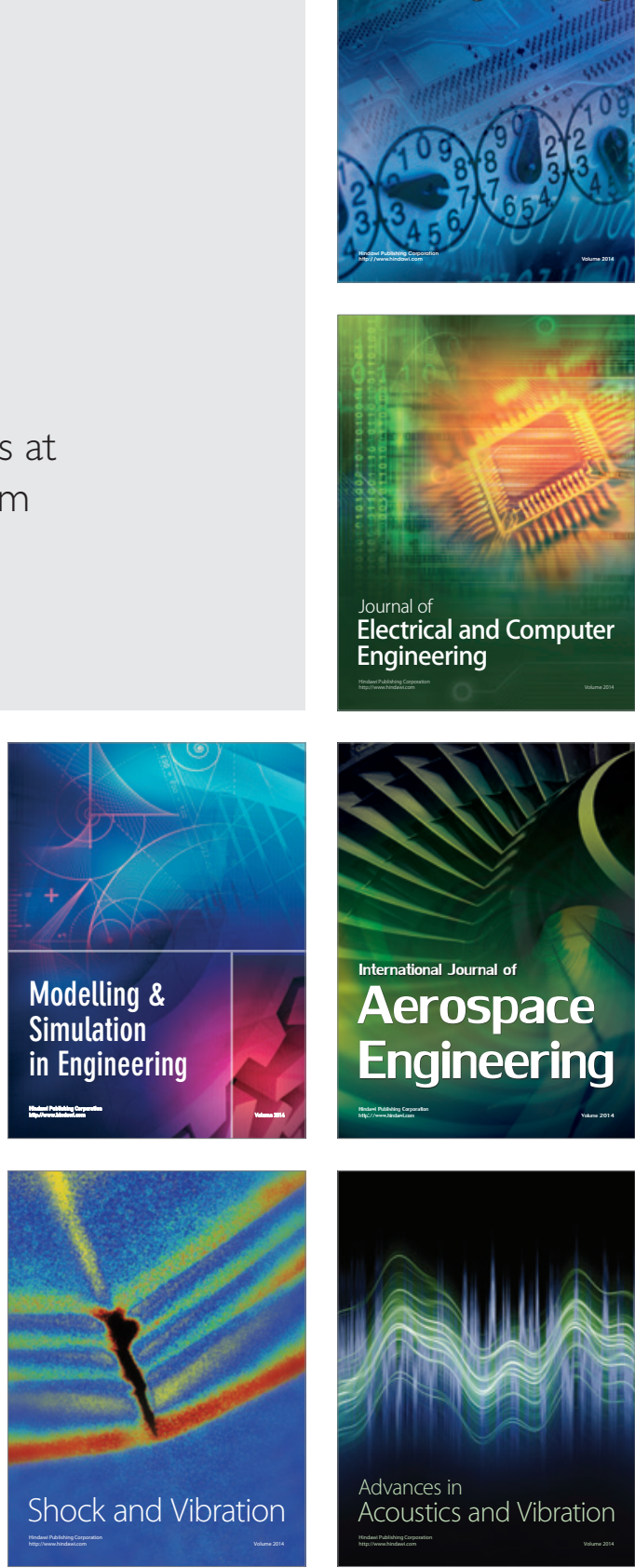